\title{
Comparison of Thermo-Hydraulic Properties of Heat Regenerators Applicable to Active Magnetic Refrigerators
}

\author{
Alen Šarlah* - Jaka Tušek - Alojz Poredoš \\ University of Ljubljana, Faculty of Mechanical Engineering, Slovenia
}

This paper describes passive heat regenerators appropriate for active magnetic refrigerators (AMR) and evaluates them from the point of view of thermo-hydraulic characteristics and magnetic properties. A dimensionless numerical model for the determination of the heat transfer coefficient is used together with experimental data for the evaluation of six different regenerator geometries using heat transfer, pressure drop and thermal efficiency as evaluation criteria. An existing numerical model was upgraded with magnetic properties and employed in the computer programme for an active magnetic regenerator in which the magnetic properties are obtained using molecular field approximation. The model was tested for thermodynamic consistency and verified using available experimental data.

(C)2011 Journal of Mechanical Engineering. All rights reserved.

Keywords: magnetic refrigeration, active magnetic regenerator, thermo-hydraulic properties

\section{INTRODUCTION}

Heat transfer coefficient and pressure drop are two most important parameters that directly determine the efficiency of the passive regenerators (PR) and consequently active magnetic regenerators (AMR). In order to obtain both parameters, regenerator needs to be experimentally tested and numerically evaluated in order to determine its thermal $-j(R e)-$ and hydraulic - $f(R e)-$ properties. There exist several techniques for prediction of heat transfer coefficients, each with its own advantages and disadvantages [1] and [2], while one of the most popular one being the single blow technique introduced by Mullisen and Loehrke [3]. The other very common technique is a steady state experimental determination of heat transfer coefficients. Several authors [1] and [2] have performed comparisons of various methods for the evaluation of the single blow technique and a proper prediction of heat transfer coefficients. They have concluded that there are significant differences between various techniques and methods, i.e. results can differ for as much as $20 \%$ [1], which is significantly more than the uncertainty of a particular method (between 4 and $10 \%$ ). For this reason it is important that the right technique and method are chosen and applied for a determination of the regenerator's heat transfer coefficient. Furthermore, in recent years, there has been a constant need to discover new, advanced regenerator geometries with higher efficiencies for which data are scarce or not yet available. Also, a lot of data on heat transfer coefficients of various heat exchangers, which are available in publications, are for certain regenerator geometries (packed bed, honeycomb, wavy structure, perforated plates). These can differ from the ones used in magnetic refrigerators due to slightly varying geometrical parameters or imperfect manufacturing. To summarize, determination of the regenerator's heat transfer coefficient is a first step of the path to a complete description of the active magnetic regenerator.

The second part of the problem is the development of a corresponding numerical model, which can appropriately describe the magnetocaloric effect and simulate the operation of an AMR. Of course, it is reasonable to use the same tool-same numerical model, which includes all influential thermodynamic and hydrodynamic properties - for both the determination of the heat transfer coefficient of the PR and, in an upgraded form, for the simulation of the AMRR operation. Here we are faced with the problem of properly introducing the magnetocaloric properties into the model. In order to describe the magnetocaloric effect as precisely as possible, we have to make sure that it is thermodynamically consistent at all stages of refrigeration cycle, while at the same time computationally efficient. In the first step this requires a careful determination and 
evaluation of magnetocaloric properties of the magnetic material. Here we are faced with certain experimental and analytical limits, which require an indirect approach to the problem [4] and [5]. In the second step, obtained properties need to be properly introduced into the model and verified for their suitability. The latter can be performed by comparing numerical results with experimental data, which would be the last step in the process. The verified model can then be used as a tool for predicting the AMR operation of various regenerators, magnetic materials, magnetic fields and operational set-ups. The objective of this paper is to summarize the procedure and results obtained using a dimensionless model which can, with certain assumptions, be equally used for both purposes: the determination of the regenerator's heat transfer coefficient and the simulation of the AMR refrigerator. Such model, in dimensionless form, can thus be a valuable tool for studying AMRR operation and later in a developing stage for the AMR design optimization.

\section{EVALUATION OF PASSIVE REGENERATORS}

The dimensionless thermo-hydraulic model for determining the passive regenerator's characteristics is extensively described and presented by Sarlah et al. [6] and [7]. The derived model was used to evaluate various types of regenerators in order to determine their characteristics and performance. The evaluated geometries are shown in Fig. 1 and presented in Table 1. While Table 2 shows uncertainty and sensitivity analysis for heat transfer and pressure drop results according to the uncertainties of a particular variable for experimental run $\# 026$.

A single blow experiment was performed to determine the heat transfer coefficient (Colburn $j$ factor) of each regenerator, and standardized pressured drop measurements were performed for determination of friction loss factor $f$. As seen in Fig. 2, absolute pressure drop significantly differs between various geometries of regenerators and thus plays a major role on the efficiency of the regenerator in AMR.

According to the results of the experimental determination of heat transfer coefficient and pressure drop, we can draw the following conclusions:

- The packed bed regenerator filled with spheres has a significantly higher pressure drop than the other regenerators, and on the other hand only modestly higher Colburn $j$-factor, which altogether makes it less desirable according to the $j / f$ ratio (Fig. 2).

- Regenerator with triangular passages and perforated plates is also not desirable, since it provides only slightly improved heat transfer, but significantly higher pressure drop (Figs. 3 and 4).

- Best $j / f$ ratio is shown by the regenerator with parallel plates (regenerator F), which has highest $j$-factor among honeycomb-like regenerators, and only a modest increase in pressure drop as compared to matrix with triangular passages.

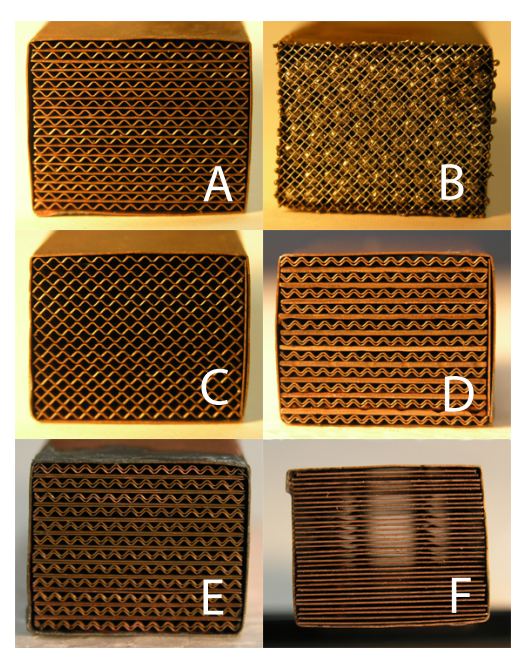

Fig. 1. Photos of six regenerator geometries experimentally tested for heat transfer and pressure drop; a) alternative flat and corrugated lamellas, b) packed bed of spheres, c) back-toback oriented lamellas, d) alternative corrugated and perforated flat lamellas, e) alternating flat and corrugated lamellas (double thickness), f) parallel lamellas

- Regenerator $\mathrm{C}$ also shows a high $j / f$ value. However, since its porosity is much higher (0.68) than in case of regenerator $\mathrm{F}(0.56)$, its cooling capacity in magnetic refrigerator, would be lower due to less magnetic material. 
This fact makes it less favourable for use in AMR as compared with others (Fig. 5).

- Regarding only the experimental results of the thermo-hydraulic properties of the various

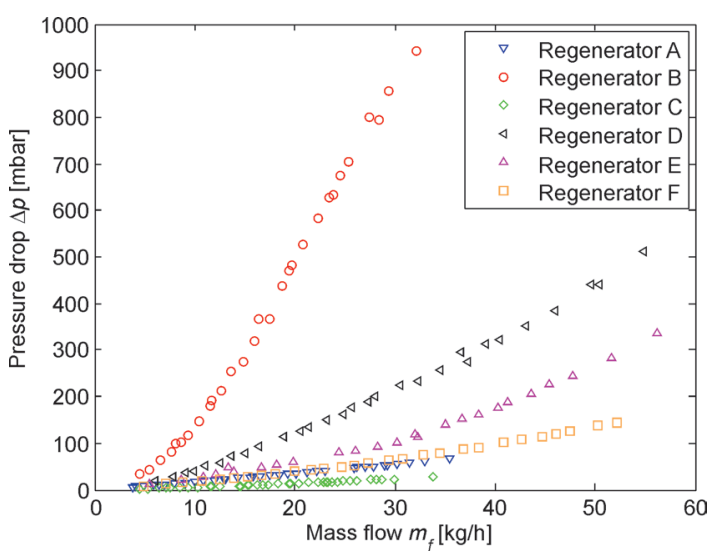

Fig. 2. Quantitative comparison of a pressure drop $\triangle p$ as a function of mass flow $m_{f}$ for all regenerators

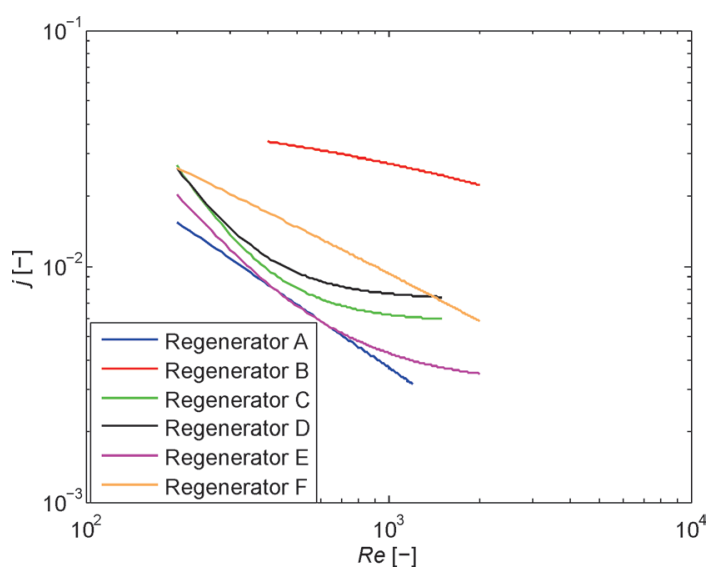

Fig. 4. Correlations of experimental data of Colburn j-factor for all regenerators (best-fit curves according to the experimental data) regenerators, parallel plate $(\mathrm{F})$ or square channels $(\mathrm{C})$ regenerator would be the best choice for use in AMR.

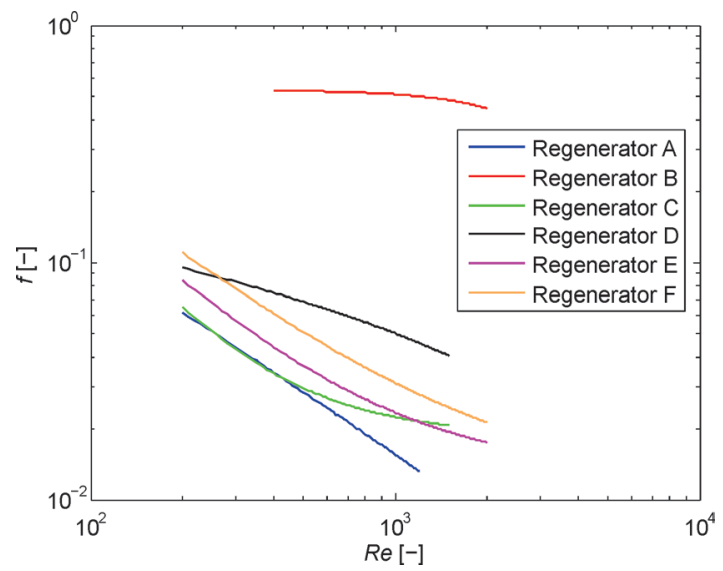

Fig. 3. Correlations of friction loss factor $f$ for all regenerators (best-fit curves according to the experimental data)

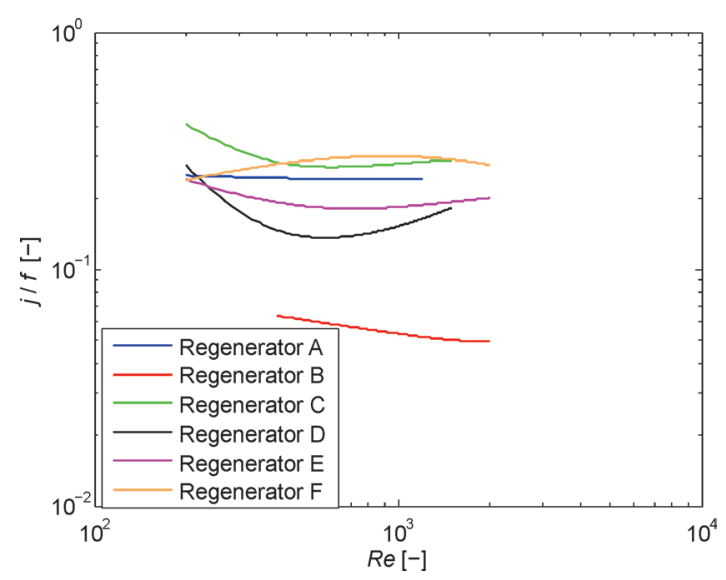

Fig. 5. Ratio of Colburn j-factor and friction loss factor $f$ as a function of Re number

Table 1. Geometrical properties of regenerators

\begin{tabular}{|c|c|c|c|c|c|c|c|}
\hline Property & Unit & A. & B. & C. & D. & E. & F. \\
\hline Material & & copper & steel & copper & copper & copper & copper \\
\hline Reg. size & $\mathrm{mm}$ & \multicolumn{6}{|c|}{$60.0 \times 20.0 \times 16.0$} \\
\hline$\delta$ & $\mathrm{mm}$ & 0.2 & 2.0 & 0.2 & 0.4 & $0.4 / 0.5$ & 0.2 \\
\hline$d_{h}$ & $\mathrm{~mm}$ & 0.48 & 0.85 & 0.79 & 0.42 & 0.50 & 0.59 \\
\hline$\varepsilon$ & - & 0.512 & 0.39 & 0.68 & 0.487 & 0.384 & 0.562 \\
\hline$a_{p}$ & $\mathrm{~m}^{2} / \mathrm{m}^{3}$ & 4273 & 1842 & 3445 & 4644 & 3063 & 3812 \\
\hline$L / d_{h}$ & - & 125 & 70.5 & 76 & 143 & 120 & 102 \\
\hline
\end{tabular}


Table 2. Uncertainty and sensitivity analyses for heat transfer and pressure drop results according to the uncertainties of a particular variable for experimental run \#26

\begin{tabular}{|c|c|c|c|c|c|c|}
\hline \multicolumn{3}{|c|}{ Run \#026 } & $\alpha\left[\mathrm{W} / \mathrm{m}^{2} \mathrm{~K}\right]$ & $j[-]$ & $f[-]$ & $\operatorname{Re}[-]$ \\
\hline \multicolumn{3}{|c|}{ Calculated values } & 187.45 & 0.00419 & 0.0148 & 868.1 \\
\hline Variable & & $u_{v}$ & $\Delta \alpha$ & $\Delta j$ & $\Delta f$ & $\Delta R e$ \\
\hline & Unit & $\% 1$ & $\%$ & $\%$ & $\%$ & $\%$ \\
\hline$\rho_{f}$ & $\mathrm{~kg} / \mathrm{m}^{3}$ & 0.50 & 0.01 & 0.29 & 0.50 & -0.44 \\
\hline$c_{f}$ & $\mathrm{~J} / \mathrm{kgK}$ & 0.50 & 0.49 & 0.31 & - & 0.00 \\
\hline$\lambda_{f}$ & $\mathrm{~W} / \mathrm{mK}$ & 0.50 & -0.50 & -0.38 & - & 0.05 \\
\hline$v_{f}$ & $\mathrm{~m}^{2} / \mathrm{s}$ & 0.50 & - & 0.29 & - & -0.43 \\
\hline$T_{f}$ & ${ }^{\circ} \mathrm{C}$ & 0.20 & 0.00 & -0.02 & - & 0.04 \\
\hline$m_{f}$ & $\mathrm{~kg} / \mathrm{s}$ & 2.69 & 2.71 & -0.02 & -5.17 & 2.74 \\
\hline$\rho_{s}$ & $\mathrm{~kg} / \mathrm{m}^{3}$ & 0.51 & 0.00 & -0.02 & - & 0.03 \\
\hline$c_{S}$ & $\mathrm{~J} / \mathrm{kgK}$ & 0.96 & 0.01 & -0.05 & - & 0.06 \\
\hline$\lambda_{s}$ & $\mathrm{~W} / \mathrm{mK}$ & 0.53 & -0.01 & 0.00 & - & -0.01 \\
\hline$L$ & $\mathrm{~m}$ & 0.17 & - & -0.21 & -0.17 & 0.07 \\
\hline$A_{r}$ & $\mathrm{~m}^{2}$ & 0.80 & 0.01 & 0.76 & 1.61 & -0.71 \\
\hline$\varepsilon$ & - & 0.99 & 0.97 & 0.93 & 3.92 & 0.04 \\
\hline$a_{p}$ & $\mathrm{~m}^{2} / \mathrm{m}^{3}$ & 1.40 & -2.68 & -1.36 & - & -1.33 \\
\hline$d_{h}$ & $\mathrm{~m}$ & 1.49 & - & -0.05 & 2.38 & 1.58 \\
\hline$\Delta_{p}$ & $\mathrm{~Pa}$ & 0.075 & - & - & 0.14 & - \\
\hline \multicolumn{3}{|c|}{$U_{R}$} & 7.48 & $1.77 \cdot 10^{-4}$ & $7.16 \cdot 10^{-4}$ & 27.67 \\
\hline \multicolumn{3}{|c|}{$u_{R}[\%]$} & 3.99 & 4.22 & 7.12 & 3.19 \\
\hline
\end{tabular}

${ }^{1}$ Percentage [\%] unless otherwise stated.

\section{MAGNETOCALORIC PROPERTIES}

The dimensionless thermo-hydraulic model used in the determination of the thermo-hydraulic properties of passive heat regenerators was upgraded for the simulation of AMR operation, i.e., it was supplemented with magnetocaloric properties of magnetic material and operational properties of AMR. Magnetocaloric properties were obtained using molecular field approximation (MFA) as proposed by Hashimoto et al. [8]. In order to use a proposed dimensionless model described in Sarlah et al. [6] and [7], two physical properties of magnetocaloric material must be numerically obtained using MFA, which is based on solid state physics: the temperature dependency of the partial derivative of entropy with respect to magnetic field $\left(\partial s / \partial \mu_{0} H\right)$ and the temperature dependency of the specific heat $\mathrm{cH}$. Both dependencies are presented in Figs. 6 and 7 for gadolinium $(\mathrm{Gd})$, which was chosen as a basic magnetocaloric material.

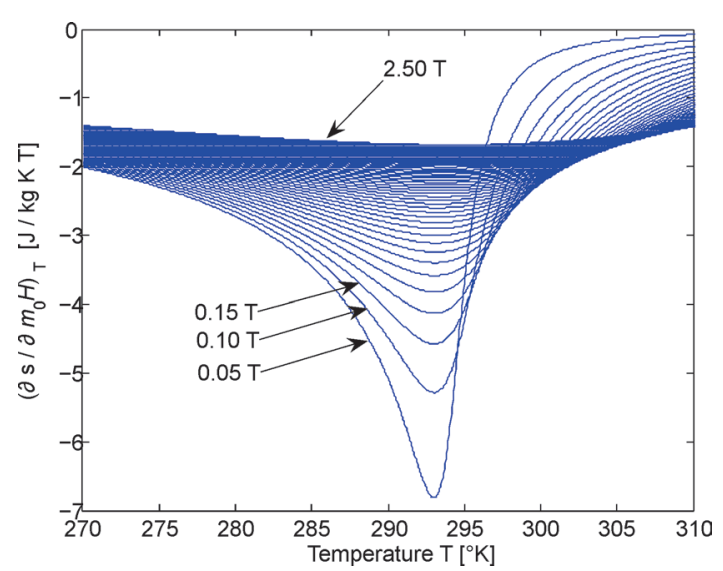

Fig. 6. Partial derivative of entropy with respect to magnetic field $\partial s / \partial \mu_{0} H$

\section{NUMERICAL MODEL OF AMR}

Insertion and employment of magnetocaloric properties into the numerical model for AMR allows us to simulate the operation of AMRR under different operating conditions and using various materials and 
fluids. The model has been verified accordingly: as proposed by Bačlić and Dragutinović [9], Engelbrecht et al. [10], and as appropriate for numerical stability and convergence of numerical results. Numerical model allows us to study the principle of operation of AMR, its refrigeration cycle, and to predict the operation (maximum temperature span and cooling load) of the device. Fig. 8 shows the refrigeration cycle of three layers of magnetocaloric material within the regenerator (entrance, middle and exit layers) during a steadystate operation of the AMR.

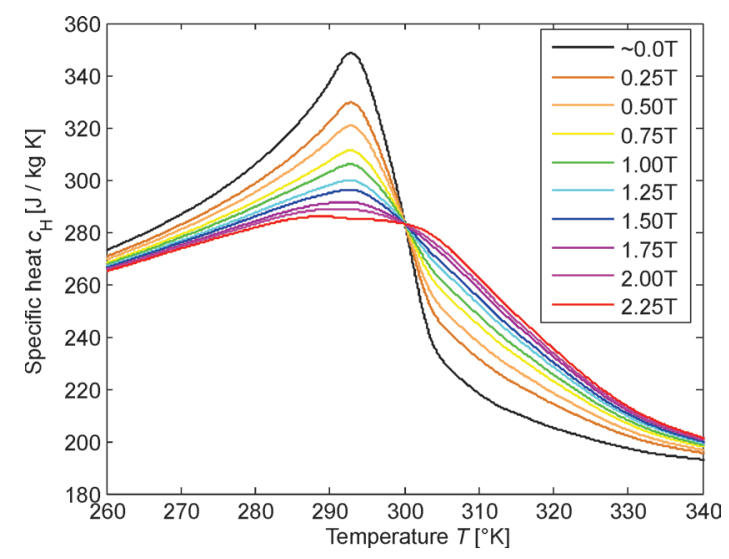

Fig. 7. Dependency of magnetic material's specific heat $c_{H}$ on temperature $T$ and magnetic field $\mu_{0} H$

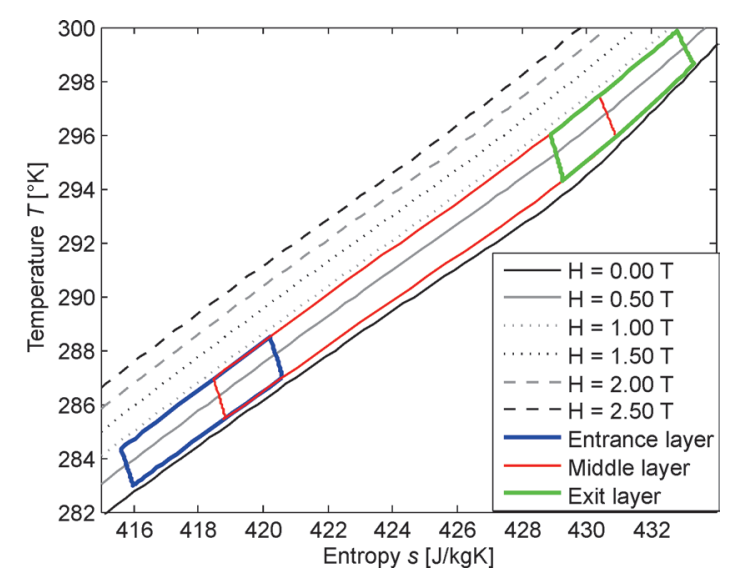

Fig. 8. Refrigeration cycles of three layers within the magnetocaloric material

The model has been verified against experimental data obtained by Kawanami [11], who has performed a wide variety of tests using a reciprocating test bed. Initially the model has significantly over-predicted the results due to a reduced magnetocaloric effect (MCE) of the sample used during the experiments, i.e., the difference between MCE of the sample and the MCE as used in the model and obtained with MFA was substantial [7]. After introduction of the correction factor the agreement of the numerical and experimental data has improved significantly. The correction factor is explained in details in Sarlah [7]. The verified model was later used for evaluation of regenerator geometries that have been previously experimentally tested. As it can be seen on Fig. 9, both experimental and analytical results show all four steps of the AMR process. Analytical model agrees very well with the experimental regarding the description of each AMR step (Fig. 9). All four cycles can be clearly seen: magnetization (warming of the material due to MCE), cooling of the material (due to heat transfer from material to the fluid), demagnetization (rapid drop in the temperature due to MCE effect, and heating of the material (due to heat transfer from the fluid to the material). The difference between both results can be observed in the amplitude of each step during the transient response - achieved temperature on the cold/hot side. This is due to the thermal mass of the heat exchanger and losses such as fluid dispersion, which reduce the temperatures span (and consequently the cooling load) of the AMRR. However, the end result of both, numerical model and the experiment agree very well once the steady-state operation is reached [7].

The following conclusions can be made:

- Temperature span of the regenerator strongly depends on the cooling load of the AMR. According to our results temperature span and cooling load are inversely proportional when a single layer of $\mathrm{Gd}$ is used as a magnetic material.

- Each regenerator geometry has an optimal length-to-hydraulic diameter ratio at which $C O P$ is highest and should be designed appropriately [7].

- Comparing all regenerators from the point of view of their thermo-hydraulic and magnetic properties, we can conclude that parallel plate regenerators display best $C O P$ values, 
mainly due to their high $j / f$ ratio. On the other hand, packed bed regenerators show highest temperature difference, but lowest $C O P$ values.

- According to the initial experimental results by some other researchers [12], parallel plate geometries showed somewhat disappointing AMR operation, signifying that some other, even better, 'advanced' regenerator geometries are required.

\section{CONCLUSION}

Experimental and numerical evaluation of various kinds of heat regenerators has been performed from the perspective of heat transfer and pressure drop. From the point of view of the performance of passive heat exchangers, the best result was shown by parallel plate heat exchanger ( $j / f$ ratio). However, when introducing magnetic properties, packed bed regenerator shows highest temperature difference due to an increased heat transfer, while it shows the lowest $C O P$ due to the highest pressure drop. For the future development of magnetic refrigeration it is crucial, that some new 'advanced' regenerator geometries are employed, which would show both an improved $C O P$ and temperature difference.

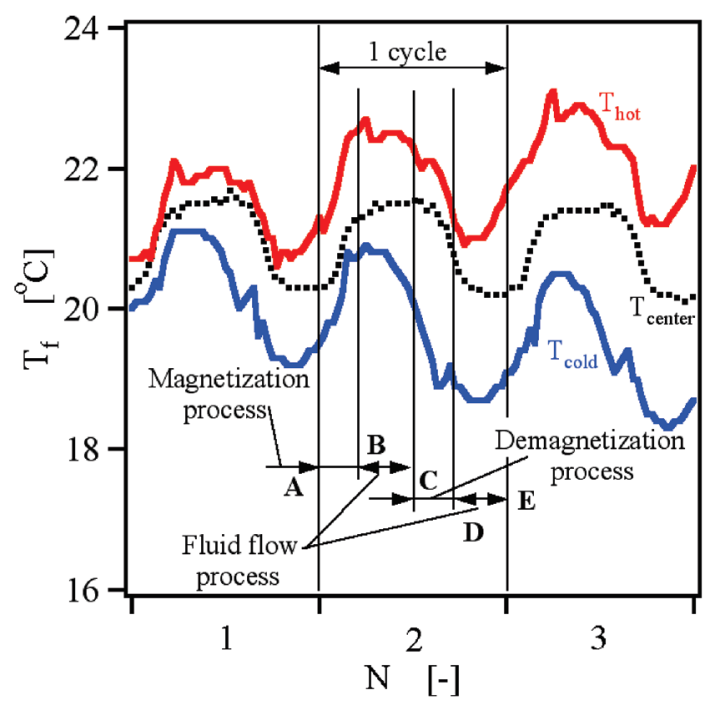

\section{NOTATION}

$\begin{array}{lll}a_{p} & \text { packing factor } & {[-]} \\ A_{f} & \text { free cross-section area } & {\left[\mathrm{m}^{2}\right]} \\ A_{r} & \text { reg. cross-section area } & {\left[\mathrm{m}^{2}\right]} \\ A_{h t} & \text { heat transfer area } & {\left[\mathrm{m}^{2}\right]} \\ c & \text { specific heat } & {[\mathrm{J} / \mathrm{kgK}]} \\ d_{h} & \text { hydraulic diameter } & {[\mathrm{m}]} \\ C O P & \text { coefficient of performance }[-] \\ \Delta \mathrm{p} & \text { pressure drop } & {[\mathrm{bar}]} \\ f & \text { Friction loss factor } & {[-]} \\ H & \text { magnetic field strength } & {[\mathrm{A} / \mathrm{m}]} \\ j & \text { Colburn factor } & {[-]} \\ L & \text { length } & {[\mathrm{m}]} \\ m_{f} & \text { mass flow } & {[\mathrm{kg} / \mathrm{s}]} \\ N u & \text { Nusselt number } & {[-]} \\ P r & \text { Prandtl number } & {[-]} \\ R e & \text { Reynolds number } & {[-]} \\ s & \text { specific entropy } & {[\mathrm{J} / \mathrm{kg} \mathrm{K}]} \\ S t & \text { Stanton number } & {[-]} \\ T & \text { temperature } & {\left[{ }^{\circ} \mathrm{C}\right]} \\ \mathrm{u} & \text { uncertainty } & {[\%]} \\ v_{\text {int }} & \text { interstitial velocity } & {[\mathrm{m} / \mathrm{s}]} \\ \alpha & \text { heat transfer coefficient } & {\left[\mathrm{W} / \mathrm{m}{ }^{2} \mathrm{~K}\right]} \\ \delta & \text { material thickness } & {[\mathrm{m}]} \\ \varepsilon & \text { porosity } & {[-]} \\ \lambda & \text { thermal conductivity } & {[\mathrm{W} / \mathrm{mK}]} \\ \rho & \text { density } & {\left[\mathrm{kg} / \mathrm{m}^{3}\right]} \\ v & \text { kinematic viscosity } & {[\mathrm{m} 2 / \mathrm{s}]} \\ \mu_{0} & \text { permeability of vacuum } & {[\mathrm{Wb} / \mathrm{Am}]} \\ & & \end{array}$

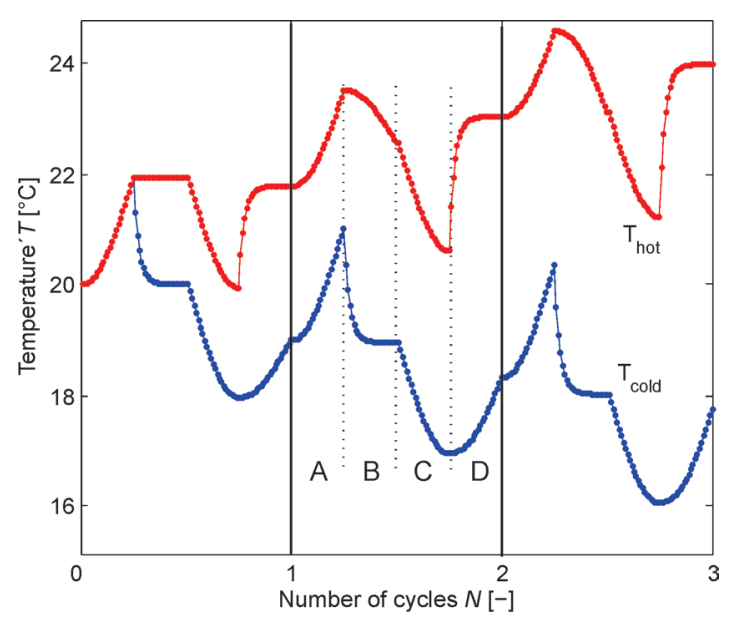

Fig. 9. Comparison of experimental (Kawanami [11]) and numerical results of the operation of AMR 
Index

$f \quad$ fluid

$H \quad$ constant magnetic field

$s \quad$ solid

$v \quad$ variable

Additional notation definitions:

$$
\begin{gathered}
j=S t \cdot \operatorname{Pr}^{2 / 3}=\frac{N u_{d}}{R e_{d} \cdot \operatorname{Pr}} \cdot \operatorname{Pr}^{2 / 3}= \\
=\frac{\alpha \cdot A_{f}}{\dot{m}_{f} \cdot c_{f}} \cdot\left(\frac{v_{f} \cdot \rho_{f} \cdot c_{f}}{\lambda_{f}}\right), \\
N u_{d}=\frac{\alpha \cdot d_{h}}{\lambda_{f}}, \\
\operatorname{Re}_{d}=\frac{v_{\text {int }} \cdot d_{h}}{v_{f}}=\frac{4 \cdot \dot{m}_{f}}{v_{f} \cdot \rho_{f} \cdot A_{r} \cdot \alpha_{p}}, \\
\frac{\Delta p_{\text {exp }}}{L} \cdot \frac{d_{h}}{2 \cdot \rho_{f} \cdot v_{i n t}^{2}}=\frac{\Delta p_{\exp }}{L} \cdot \frac{\rho_{f} \cdot d_{h} \cdot A_{f}^{2}}{2 \cdot \dot{m}_{f}^{2}}, \\
d_{h}=\frac{4 \cdot V_{f}}{A_{h t}}=\frac{4 \cdot \varepsilon}{\alpha_{p}} .
\end{gathered}
$$

\section{REFERENCES}

[1] Heggs, P.J., Burns, D. (1988). Single-blow experimental prediction of heat transfer coefficients. Experimental Thermal and Fluid Science, vol. 1, no. 3, p. 243-251, DOI:10.1016/0894-1777(88)90003-9.

[2] Shah, R.K., Zhou, S.Q. (1997). Experimental techniques for obtaining design data of compact heat exchanger surfaces. Proceedings of the International Conference on Compact Heat Exchangers for the Process Industries, Snowbird, p. 365-379.

[3] Mullisen, R.S., Loehrke, R.I. (1986). A transient heat exchanger evaluation test for arbitrary fluid inlet temperature variation and longitudinal core conduction. ASME Journal of Heat Transfer, vol. 108, p. 370-376, DOI:10.1115/1.3246932.

[4] Tishin, A.M., Spichkin, Y.I. (2003). The magnetocaloric effect and its applications. Institute of Physics Publishing, DOI:10.1887/0750309229.

[5] Pecharsky, V.K., Gschneidner, Jr., K.A. (1999). Magnetocaloric effect and magnetic refrigeration. Journal of Magnetism and Magnetic Materials, vol. 200, p. 44-56, DOI:10.1016/S0304-8853(99)00397-2.

[6] Sarlah, A., Poredos, A. (2007). Dimensionless numerical model for determination of magnetic regenerator's heat transfer coefficient and its operation. $2^{\text {nd }}$ International Conference on Magnetic Refrigeration at Room Temperature, Conference Proceedings, p. 231-238.

[7] Sarlah, A. (2008). Thermo-hydraulic properties of heat regenerators in magnetic refrigerator. $\mathrm{PhD}$. Thesis, University of Ljubljana, Ljubljana.

[8] Hashimoto, T., Numasawa, T., Shino, M., Okada, T. (1981). Magnetic refrigeration in the temperature range from $10 \mathrm{~K}$ to room temperature: the ferromagnetic refrigerants. Cryogenics, vol. 21, no. 11, p. 647-653, DOI:10.1016/0011-2275(81)90254-X.

[9] Bačlić, B.S., Dragutinović, G.D. (1998). Operation of counterflow regenerators. Computational Mechanics Inc., Southampton.

[10] Engelbrecht, K., Nellis, G., Klein, S. (2005). A numerical model of an active magnetic regenerator refrigeration system. Final Report. ARTI-21CR/612-10075, University of Wisconsin - Madison.

[11] Kawanami, T. (2007). Heat transfer characteristics and cooling performance of an active magnetic regenerator. $2^{\text {nd }} I I F$ IIR International Conference on Magnetic Refrigeration at Room Temperature Conference Proceedings, p. 197-209.

[12]Zimm, C., Auringer, J., Boeder, A., Chell, J., Russek, S., Sternberg, A. (2007). Design and initial performance of a magnetic refrigerator with a rotating permanent magnet. $2^{n d} I I F-$ IIR International Conference on Magnetic Refrigeration at Room Temperature Conference Proceedings, p. 252-261. 